\title{
PRODUÇÃO DE BIODIESEL METÍLICO DE ÓLEO DE CATOLÉ POR TRANSESTERIFICAÇÃO ALCALINA
}

\author{
S. P. da SILVA ${ }^{1}$, P. H. de SOUZA ${ }^{1}$, V. N. e MELO ${ }^{2}$, A. C. P. F. da SILVA ${ }^{3}$, A. R. P. \\ SCHULER $^{3}$
}

${ }^{1}$ UAST - UFRPE - Unidade Acadêmica de Serra Talhada - Universidade Federal Rural de Pernambuco.

${ }^{2}$ DQ - UFRPE - Departamento de Química - Universidade Federal Rural de Pernambuco.

${ }^{3}$ LCI-DEQ-UFPE - Laboratório de Cromatografia Instrumental - Departamento de Engenharia Química - Universidade Federal de Pernambuco.

E-mail para contato: suzanapedroza24@yahoo.com.br

\begin{abstract}
RESUMO - No semi-árido brasileiro, várias oleaginosas têm sido utilizadas para a obtenção de óleos vegetais, dentre as diversas espécies que formam a flora da Caatinga, o Catolé, Syagrus cearensis. Foram feitas análises de teor de ésteres por cromatografia gasosa em $300 \mathrm{~mL}$ de gordura obtida de dois quilos da amêndoa. $\mathrm{Na}$ fase de transesterificação observou-se que o biodiesel apresentou coloração

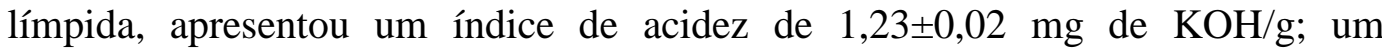
percentual de ácidos graxos livres de $0,86 \pm 0,02 \%$ e uma viscosidade cinemática de $30,76 \pm 1,17 \mathrm{~mm}^{2} / \mathrm{s}$. Foram observados dez tipos de ésteres no biodiesel de catolé (C8; C10; C12; C14; C16; C18:0; C18:1; C18:2 e, C18:3), em maior percentual o 18:2, 18:1 e o 16:0, os quais dão melhor qualidade ao biodiesel, com pureza real de aproximadamente $70 \%$. As análises classificaram o biodiesel de óleo de catolé como mais uma matéria prima disponível no sertão Nordestino - PE para a produção de biodiesel.
\end{abstract}

\section{INTRODUÇÃO}

$\mathrm{Na}$ década de 70 instaurou-se uma grande crise mundial do petróleo como matriz energética, pesquisas realizadas com fontes renováveis de energia foram sendo testadas principalmente com óleos vegetais (KNOTHE et al., 2006). Rudolph Diesel, inventor do motor à combustão interna que leva seu nome, utilizou em seus ensaios petróleo cru e óleo de amendoim. Devido ao baixo custo e alta disponibilidade do petróleo à época, este passou a ser o combustível largamente usado nestes motores (SUAREZ et al., 2007). A essa mistura de óleos deu-se o nome de biodiesel

O biodiesel pode ser obtido através de um processo de transesterificação, no qual ocorre a transformação de triglicerídeos em moléculas menores de ésteres de ácidos graxos através da ação de um álcool e um catalisador ácido ou alcalino, visando reduzir a viscosidade dos óleos vegetais (FERRARI et al., 2004). Este novo combustível emite maior número de cetano, causa menos agressão ao meio ambiente, gera emprego e renda, promove o desenvolvimento de novas tecnologias, expande o setor agrícola, incentiva à produção sustentável de espécies nativas como babaçu, dendê, macaúba, catolé, todas da família palmae presentes nos biomas brasileiros (CADERNOS NAE, 2005). 
O óleo de catolé foi utilizado como matéria-prima de investigação desta pesquisa por apresentar uma quantidade de lipídeos superior a $60 \%$ em suas amêndoas (FARIAS et al., 2012) da qual obteve-se o óleo, submetido a vários processos físicos e químicos. O catolé (Syagrus cearensis) é um coco (coco-catolé, ou coco-ouricuri) proveniente de uma palmeira, da flora brasileira presente no Cerrado, Mata Atlântica e Caatinga, rico em gorduras e com um leite rico em macronutrientes e micronutrientes. Seus maiores cultivadores estão localizados no Nordeste e nos estados de Pernambuco e Bahia, no Brasil. Existem outros frutos do mesmo gênero do catolé, família da palma. Sua árvore tem cerca de 3 a 5 metros de altura (Figura 1a). As flores são pequenas, reunidas em cachos (Figura 1b) que surgem predominantemente de maio a agosto (Figura 2a), embora floresça e frutifique durante todo o ano, amadurecendo (Figura $2 b$ ) no período de outubro a dezembro. A produção média anual é de $2.000 \mathrm{~kg} / \mathrm{ha}$ de frutos, podendo alcançar $4000 \mathrm{~kg} / \mathrm{ha}$. Sua amêndoa, rica em óleo vegetal (35 à 38\%), extraída artesanalmente por habitantes da região. O coqueiro gosta de clima quente e úmido (LORENZI, 1992). São muitos seus usos, confecções de artigos regionais tais como: chapéus de palha, vassouras, bolsas (folhas); banquetas de decoração (tronco); ração animal, na culinária, leite, óleo, (extração das amêndoas). Além de uso terapêutico no tratamento de problema de estômago, erisipela, diarréia e diurético (ROSA et al., 2012).

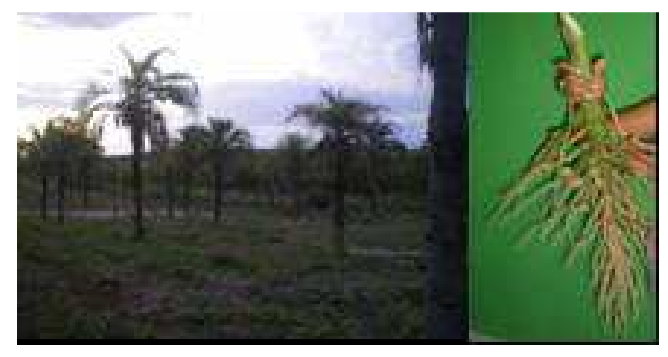

Figura 1 - a) plantação do coco-catolé, b) cacho do catolé.

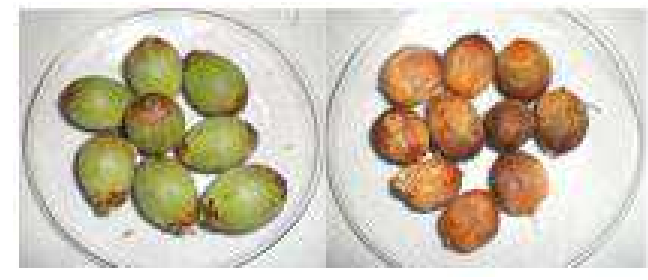

Figura 2 - a) catolé verde, b) catolé maduro.

O presente trabalho teve como objetivos: a obtenção do índice de pureza, identificação do percentual de ésteres e ácidos graxos livres, determinação de acidez e viscosidade cinemática, tanto do óleo como do biodiesel produzido, caracterização do catolé como uma oleaginosa.

\section{MATERIAL E MÉTODOS}

\subsection{Coleta e Processamento dos Frutos}

A área de coleta está localizada no município de São José do Belmonte (PE) a $473 \mathrm{~km}$ de Recife, numa propriedade rural. Em São José do Belmonte, a uma altitude de 486 m, onde 
o clima é do tipo tropical semi-árido quente, com chuvas de verão. O período chuvoso se inicia em novembro com término em abril. A precipitação média anual é de $431,8 \mathrm{~mm}$. A Temperatura média anual $25,2{ }^{\circ} \mathrm{C}$.

Os frutos de Syagrus cearensis de cachos ainda presos à planta foram coletados no mês de outubro de 2011. Foram escolhidos os frutos secos e maduros. Após a coleta, os frutos ainda maduros foram secos ao sol por cinco dias, embalados em sacos plásticos e levados ao laboratório. Os frutos recebidos após sete dias da coleta foram submetidos à quebra do endocarpo in natura extraídos artesanalmente. Em dois quilos da amêndoa obteve-se $300 \mathrm{~mL}$ da gordura (Figura 3a e 3b).

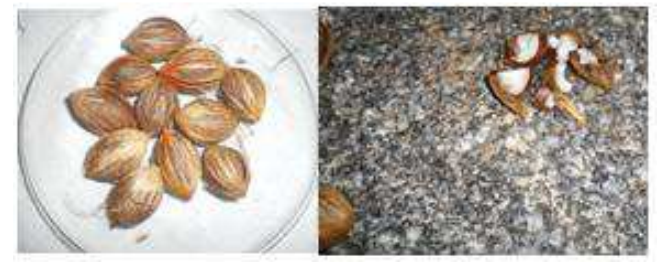

Figura 3 - a) catolé seco, b) quebra manual do catolé.

Foram feitas análises de teor de ésteres (cromatografia gasosa), teor residual de sódio (fotometria de chama) e, índice de acidez (titulometria).

\subsection{Método Analítico da Transesterificação de Triacilgliceróis}

2.2.1. Preparação do Reagente de Esterificação: pôs-se uma mistura contendo $2 \mathrm{~g}$ de cloreto de amônio $\left(\mathrm{NH}_{4} \mathrm{Cl}\right), 60 \mathrm{ml}$ de metanol $\left(\mathrm{CH}_{3} \mathrm{OH}\right)$ e $3 \mathrm{ml}$ de ácido sulfúrico $\left(\mathrm{H}_{2} \mathrm{SO}_{4}\right)$ concentrado no refluxo por 15 minutos.

2.2.2. Transesterificação: pesou-se exatamente $(\mathrm{s}=0,001 \mathrm{~g})$ uma massa próxima de 0,5 $\mathrm{g}$ da amostra em um balão de fundo chato, de $250 \mathrm{~mL}$, adicionou-se $5 \mathrm{~mL}$ de solução de hidróxido de sódio 0,5 N em metanol e pôs-se no refluxo durante 5 minutos. Adicionou-se, à solução ainda quente, $15 \mathrm{~mL}$ do reagente de esterificação e deixou-se refluxar por mais 3 minutos. Após esfriar, transferiu-se a mistura para um funil de separação e adicionou-se $5 \mathrm{~mL}$ de hexano e $10 \mathrm{~mL}$ de água saturada com cloreto de sódio. Fechou-se o funil e agitou-se vigorosamente por alguns segundos. Deixou-se em repouso para separação completa das duas fases. Após remoção da fase inferior (água, cloreto de sódio, excesso de álcool, glicerol e hidróxido de sódio) lavou-se o balão com mais $10 \mathrm{~mL}$ de água saturada com cloreto de sódio. Transferiu-se o material (mistura de ésteres metílicos dos ácidos graxos constituintes da amostra) para um recipiente âmbar e adicionou-se sulfato de sódio anidro para remoção de toda umidade. A amostra foi conservada sob refrigeração $\left(\mathrm{T}=10^{\circ} \mathrm{C}\right)$ até a realização da análise cromatográfica.

2.2.3. A quantificação dos ésteres por cromatografia a gás foi realizada da seguinte forma: as amostras foram diluídas em hexano $(40 \mathrm{mg}$ em $5 \mathrm{~mL}$ ) e analisadas por cromatografia a gás. $\mathrm{O}$ volume injetado no cromatógrafo foi de $1 \mu \mathrm{L}$ para todas as amostras. Foi utilizado para as análises cromatográficas um cromatógrafo a gás marca CG, modelo CGMaster, dotado de detector de ionização de chama; coluna capilar (megabore) de sílica fundida contendo um filme com 0,25 $\mu \mathrm{m}$ de polietilenoglicol (Carbowax $20 \mathrm{M}$ ), com $30 \mathrm{~m}$ de 
comprimento e $0,54 \mathrm{~mm}$ de espessura. A temperatura do detector foi ajustada para $200{ }^{\circ} \mathrm{C}$ e a do vaporizador para $150{ }^{\circ} \mathrm{C}$. $\mathrm{O}$ forno da coluna recebeu a seguinte programação: $70{ }^{\circ} \mathrm{C}$ durante 3 minutos; subindo $10{ }^{\circ} \mathrm{C} / \mathrm{min}$ até $175^{\circ} \mathrm{C}$, permanecendo nesta por 8 minutos; depois subiu $10{ }^{\circ} \mathrm{C} / \mathrm{min}$ até $190{ }^{\circ} \mathrm{C}$, permanecendo por 5 minutos. A fase móvel foi o hidrogênio (5 $\mathrm{mL} / \mathrm{min}$ ), com uma razão de divisão (split) de 1/20.

\subsection{Determinação do Teor Residual de Sódio}

As análises de sódio foram realizadas a partir da metodologia adaptada de Oliveira, 2007. Foram pesados $2 \mathrm{~g}$ do biodiesel em cadinho, o qual foi levado à mufla a $250^{\circ} \mathrm{C}$ durante $1 \mathrm{~h}$, elevando a temperatura em seguida para $600{ }^{\circ} \mathrm{C}$ e assim permanecendo por $4 \mathrm{~h}$, para reduzir o material a cinzas; após resfriamento dissolveu-se o resíduo inorgânico com $8 \mathrm{~mL}$ de uma solução aquosa de ácido nítrico a 1,0 \% (v/v) e filtrou-se em papel de filtro, completando-se em balão volumétrico para $10 \mathrm{~mL}$ com água destilada e deionizada, posteriormente analisada pela técnica de fotometria de chama.

\subsection{Determinação do Índice de Acidez}

O índice de acidez do biodiesel indica o teor de ácidos graxos livres. As análises foram realizadas em triplicata a partir da metodologia adaptada da empresa Meat Research Corporation (1997). O índice de acidez dos óleos corresponde à quantidade (mg) de base $(\mathrm{KOH}$ ou $\mathrm{NaOH})$ necessária para neutralizar os ácidos graxos livres presentes em cada grama de amostra. Foram pesados $2 \mathrm{~g}$ de biodiesel em erlenmeyer, adicionou-se $25 \mathrm{~mL}$ da solução dissolvente éter etílico-álcool etílico (2:1) previamente neutralizada com uma solução de hidróxido de sódio $0,01 \mathrm{M}$ e em seguida, 3 gotas de fenolftaleína. Homogeneizou-se a amostra até sua completa dissolução, titulamos com a solução de $\mathrm{NaOH}$ 0,01M padronizada até o aparecimento da coloração rósea e anotamos o volume gasto (V) .

Para o cálculo de índice de acidez utilizou-se a equação: $I A=\left(40 * V^{*} M\right) / W$

Onde: V é o volume gasto da solução de $\mathrm{NaOH}(\mathrm{mL})$; $\mathrm{M}$ é a molaridade da solução de $\mathrm{NaOH}(\mathrm{mol} / \mathrm{L})$; W é a massa de do biodiesel (g) a ser analisada.

\subsection{Determinação da Viscosidade}

A viscosidade dinâmica foi medida em um viscosímetro de Ostwald. Após o viscosímetro rigorosamente limpo e a temperatura da sala a $20{ }^{\circ} \mathrm{C}$, mede-se o tempo de deslocamento do fluido, repetindo-se o processo para o mesmo biodiesel por 5 vezes, a partir da equação: $\eta 1,2=(P 1 / P 2) *(T 1 / T 2)$

Onde: a viscosidade relativa do biodiesel em relação ao de uma solução glicerol água com valores próximos ao do biodiesel dentro de uma curva de calibração.

Finalmente, realizou-se a transformação da viscosidade dinâmica para a viscosidade cinemática. A viscosidade cinemática $\left(\nu, \mathrm{mm}^{2} \cdot \mathrm{s}^{-1}\right)$ é dada pela relação entre a viscosidade dinâmica $\left(\mu, \mathrm{g} \cdot \mathrm{m}^{-1} \cdot \mathrm{s}^{-1}\right)$ e a massa específica $\left(\rho, \mathrm{g} \cdot \mathrm{dm}^{-3}\right)$, , medidos a $40^{\circ} \mathrm{C}$, de acordo com a equação: $v=(\mu / \rho)$ 


\section{RESULTADOS E DISCUSSÃO}

Segundo a norma IN 14103 o biodiesel deve conter um teor mínimo de éster de 96,5\% em massa, sendo que de acordo com Knothe (2008) os ésteres que melhor caracterizam o biodiesel são o Linoléico (18:2), Oléico (18:1) e o Palmítico (16:0), exclusivamente o éster Linoléico (18:2) que dá a qualidade superior ao biodiesel, o que foi observado na análise cromatográfica de ésteres do o óleo de catolé transesterificado, mesmo contendo de C12 à C20 em sua composição, o que pretende ser melhor investigado e feita completa caracterização.

$\mathrm{O}$ aspecto visual do biodiesel permaneceu bem límpido, havendo uma rápida e visível separação de fases, o que é bastante positivo para purificação do produto final, como mostrado na Figura 4.

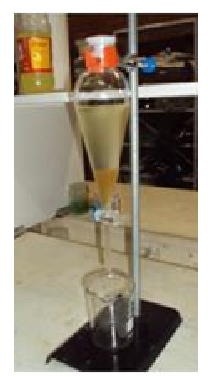

Figura 4 - Óleo de catolé transesterificado.

Como pode ser visto, tanto índice de acidez como \%AGL do óleo de Catolé Tabela 1, apresenta valores muito satisfatórios. A viscosidade cinemática do óleo (Tabela 1) é menor que de outros óleos encontrados na literatura, como encontrado em Brandão (2005) para o óleo de soja $\left(40,0 \mathrm{~mm}^{2} / \mathrm{s}\right)$.

Tabela 1- Determinação de parâmetros dos óleos usados na transesterificação.

\begin{tabular}{cc}
\hline PARÂMETROS & Óleo de Catolé \\
\hline Índice de Acidez (mg de KOH/g) & $1,23 \pm 0,02$ \\
Percentagem de Ácidos Graxos Livres $(\% \mathrm{AGL})$ & $0,86 \pm 0,02$ \\
Viscosidade Cinemática $\left(\mathrm{mm}^{2} / \mathrm{s}\right)$ & $30,76 \pm 1,17$ \\
\hline
\end{tabular}

\subsection{Caracterização dos ésteres do óleo de catolé}

Segundo a norma IN 14103 o biodiesel deve conter um teor mínimo de éster de 96,5\% em massa, e de acordo com Knothe (2008) os ésteres que melhor caracterizam o biodiesel são: o Oleico (18:1), e o Palmítico (16:0), Linoleico (18:2). Este último dá uma qualidade superior quando a concentração for maior que 50\%, biodiesel conforme Tabela 2. Para o biodiesel de óleo de Catolé estes percentuais foram todos dentro dos valores desejados. 
Tabela 2- Caracterização dos ésteres do biodiesel de óleo de catolé por cromatografia gasosa.

\begin{tabular}{cccc}
\hline Componente & Retenção & Area & Norma area \% \\
\hline C14:0 & 0,00 & 0,00 & 0,0 \\
C16:0 & 1,08 & 40,36 & 15,2 \\
C18:0 & 1,76 & 7,13 & 2,7 \\
C18:1 & 1,86 & 73,37 & 27,6 \\
C18:2 & 2,13 & 132,91 & 50,0 \\
\hline
\end{tabular}

\subsection{Parâmetros do biodiesel de catolé}

O biodiesel deve ser submetido às análises dos parâmetros que possam indicar sua qualidade, de acordo com a RESOLUÇÃO ANP $N^{\circ} 7 / 2008$. Alguns desses parâmetros, mais importantes, são o índice de acidez e a viscosidade cinemática (Tabela 3).

O índice de acidez está relacionado com a degradação do biodiesel, podendo ser, também, um indicador da ocorrência da transformação dos triglicerídeos dos óleos em seus respectivos ésteres metílicos, devendo alcançar no máximo $0,5 \mathrm{mg} \mathrm{NaOH} / \mathrm{g}$ em biodieseis. A viscosidade tem um limite mínimo de $3 \mathrm{~mm}^{2} / \mathrm{s}$, pois se a viscosidade se tornar muito baixa afeta a lubricidade do motor. Devido a este fato, é mais satisfatório o uso de misturas de diesel de petróleo com biodiesel.

Tabela 3- Determinação de parâmetros dos biodieseis obtidos pela transesterificação.

\begin{tabular}{ccc}
\hline PARÂMETROS & Catolé & $\begin{array}{c}\text { Resolução ANP } \\
\mathrm{N}^{\circ} 7 / 2008\end{array}$ \\
\hline Índice de Acidez $(\mathrm{mg}$ de $\mathrm{KOH}-\mathrm{NaOH} / \mathrm{g})$ & $0,26 \pm 0,04$ & Máximo 0,5 \\
Viscosidade Cinemática $\left(\mathrm{mm}^{2} / \mathrm{s}\right)$ & $3,48 \pm 0,17$ & 3 à 6 \\
\hline
\end{tabular}

Ao se fazer uma correlação entre a viscosidade cinemática do óleo e seu respectivo biodiesel tem-se uma redução de aproximadamente nove vezes, de $30,76 \mathrm{~mm}^{2} / \mathrm{s}$ para $3,48 \mathrm{~mm}^{2} / \mathrm{s}$; indicando uma boa eficiência da transesterificação foi atingido. Em relação ao índice de acidez pode-se destacar uma redução cerca de cinco vezes do valor inicial.

Melo (2010) aponta que outros fatores como armazenamento, qualidade de semente e de frutos e o processo de extração podem causar variações no parâmetro mencionado acima. Visto que o óleo utilizado tinha aspecto límpido e isso pode ter contribuído na obtenção resultados significativos.

\subsection{Determinação da eficiência do processo de transesterificação}

A composição centesimal do biodiesel, assim como a composição centesimal dos ácidos graxos existentes na matéria-prima é determinada por cromatografia a gás, empregando-se o método de cálculo por normalização de área. Esta composição é obtida através do método analítico, aplicada na determinação das massas moleculares do óleo e do biodiesel.

A eficiência da produção do biodiesel por transesterificação pode ser determinada de várias maneiras. Neste trabalho, buscou-se associar esta eficiência com o rendimento real de biodiesel obtido em termos de percentagem. É verificado (Tabela 4) que o biodiesel de óleo de 
catolé obteve um rendimento real de biodiesel de quase $70 \%$, o qual se deve ao fato de tanto sua pureza, como seu rendimento bruto, terem tido valores acima de $75 \%$.

Tabela 4 - Determinação de parâmetros da eficiência da transesterificação.

\begin{tabular}{cc}
\hline PARÂMETROS & Óleo/Biodiesel de Catolé \\
\hline Massa Molecular Óleo $(\mathrm{g} / \mathrm{mol})$ & $964,04 \pm 5,28$ \\
Massa Molecular Biodiesel $(\mathrm{g} / \mathrm{mol})$ & $229,65 \pm 2,53$ \\
Pureza $(\%)$ & $78,54 \pm 4,07$ \\
Rendimento bruto Biodiesel $(\%)$ & $85,53 \pm 2,04$ \\
Rendimento Real Biodiesel $(\%)$ & $67,17 \pm 0,51$ \\
\hline
\end{tabular}

Na determinação dos ácidos graxos foram observados dez tipos diferentes no biodiesel de óleo de catolé conforme apresentado na Figura 5. Verifica-se a presença de C8 (ácido caprílico), C10 (ácido cáprico), C12 (ácido láurico), C14 (ácido mirístico), C16 (ácido palmítico), C17 (heptadecanoato de metila, padrão interno), C18:0 (ácido esteárico), C18:1 (ácido oleico), C18:2 (ácido linoleico), C18:3 (ácido linolênico).

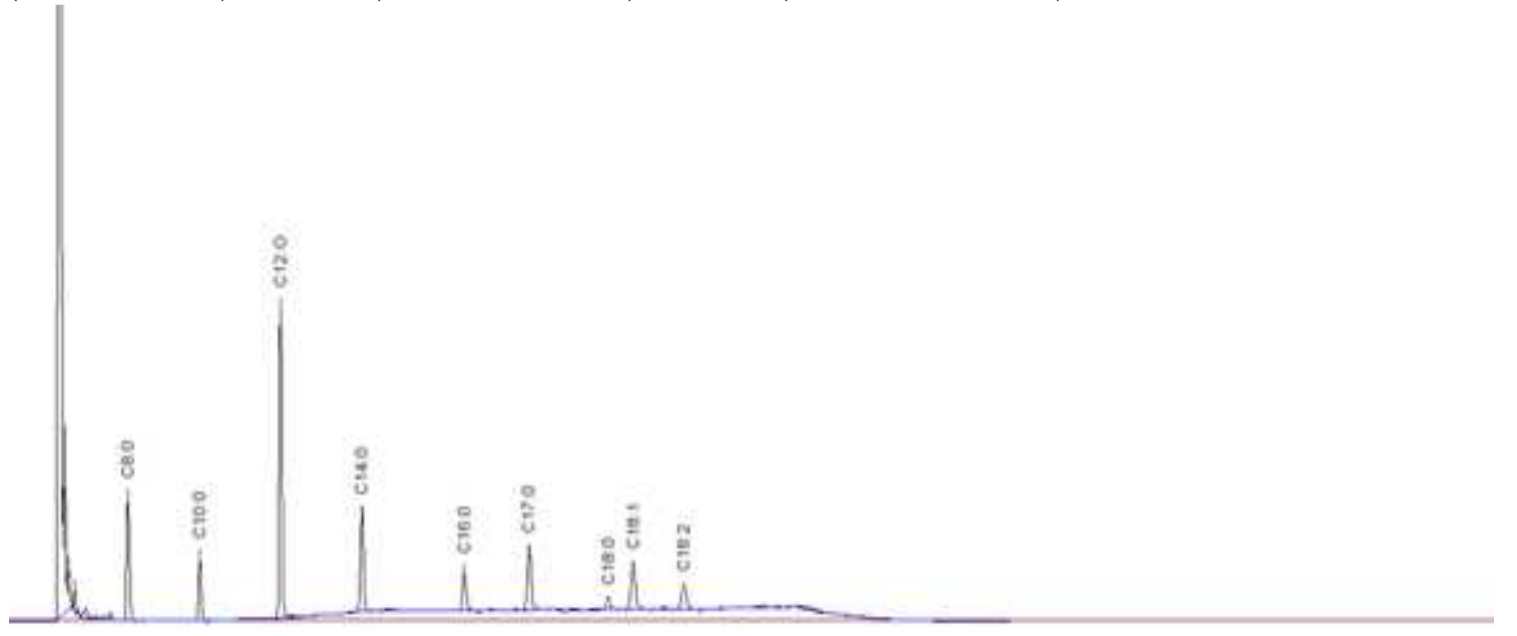

Figura 5 - Cromatograma do biodiesel do óleo de catolé.

\section{CONCLUSÃO}

Os biodieseis produzidos por transesterificação por catálise homogênea em meio básico, utilizando como matéria-prima óleo de catolé tiveram os parâmetros de índice de acidez e viscosidade cinemática em conformidade com a RESOLUÇÃO ANP $\mathrm{N}^{\circ} 7 / 2008$, no que se refere a qualidade do biodiesel. Todos os índices de acidez ficaram abaixo de 0,5 miligramas de $\mathrm{KOH}$ por grama de amostra (mg $\mathrm{KOH} / \mathrm{g}$ de amostra). E, todas as viscosidades cinemáticas ficaram entre os valores de 3 a 6 milímetros ao quadrado por segundo $\left(\mathrm{mm}^{2} / \mathrm{s}\right)$.

O biodiesel apresentou aspecto límpido, uma pureza 78,54 \% $\pm 4,07$; um rendimento bruto de $85,53 \% \pm 2,04$ e um rendimento real de $67,17(\%) \pm 0,51$. Os ácidos graxos presentes no óleo de catolé, Syagrus cearensis, são característicos de biodiesel, classificando o mesmo 
como mais uma matéria prima disponível no sertão Nordestino - PE para a produção de biodiesel. Portanto, é viável a produção do biodiesel de óleo de catolé, contribuindo para a sustentabilidade da região.

\section{REFERÊNCIAS}

CADENOS NAE. Núcleo de Altos Estudos da Presidência da República - $\mathrm{n}^{\circ}$ 2. Núcleo de Assuntos Estratégicos da Presidência da República, Secretaria de Comunicação de Governo e Gestão Estratégica. Brasília, 2005. Disponível em: <http://www.ambiente.sp.gov.br/wpcontent/uploads/publicacoes/etanol/NAEBiocombu stiveis.pdf>. Acesso em: 15 jul. 2013.

FARIAS, E. C. et al. Caracterização da Amêndoa do Coco Catolé. In: CONNEPI: Congresso Norte Nordeste de Pesquisa e Inovação, 7., 2012, Palmas. Anais eletrônicos... Palmas, 2012 Disponível em: <http://propi.ifto.edu.br/ocs/index.php/connepi/vii/schedConf/presentations?searchField $=\&$ searchMatch=\&search=\&track=57>. Acesso em: 02 jul 2013.

FERRARI, A. R.; OLIVEIRA, V. S.; SEABIO, A. Biodiesel de Soja - Taxa de Conversão em Ésteres Etílicos, Caracterização Físico-química e Consumo em Gerador de Energia. Química Nova. Vol.28, $\mathrm{n}^{\circ}$ 1, p. 19 - 23, 2005. Disponível em: <http://www.scielo.br/pdf/qn/v28n1/23031.pdf >. Acesso em: 30jul 2013.

LORENZI, H. Árvores brasileiras: manual de identificação e cultivo de plantas arbóreas nativas do Brasil. Nova Odessa: Ed. Platarum, 1992. 287 p.

HARTMAN, L., LAGO, R.C. A . Rapid preparation of fatty acid methyl ester from lipids. Londres : Lab. Pract., v. 22, p. 475-476, 1973.

KNOTHE, G. et al. Manual de Biodiesel, ed. 1. Editora Edgard Blücher: São Paulo, 2006.

KNOTHE G. Designer" Biodiesel: Optimizing Fatty Ester Composition to Improve Fuel Properties. Energy \& Fuels, 22, 1358-1364. 2008.

MELO, M.A.M.F., Avaliação das Propriedades de Óleos Vegetais visando a Produção de Biodiesel. João Pessoa, 2010. 118 p. Dissertação (Mestrado em Química). Centro de Ciências Exatas e da Natureza, Universidade Federal da Paraíba, 2010. Disponível em: <http://www.quimica.ufpb.br/posgrad/dissertacoes/Dissertacao_Maria_Andrea_Mendes _Formiga_Melo.pdf >. Acesso em: 29 jun. 2013.

ROSA, J.; JESUS, D.; DUARTE, F.; LIMA, A.; PEREIRA, V. Otimização e validação de estratégias analíticas para avaliação do teor do leite de coco do catolé. Disponível em:< http://connepi.ifal.edu.br/ocs/index.php/connepi/CONNEPI2010/paper/viewFile/81/124 > Acessado em: 27/02/2012.

SUAREZ, P. A. Z. et al. Transformação de Triglicerídeos em Combustíveis, Materiais Poliméricos e Insumos Químicos: algumas aplicações da catálise na oleoquímica. Química Nova, Vol. 30, $\mathrm{n}^{\circ}$ 3, p.667-676, 2007. Disponível em: < http://www.scielo.br/pdf/qn/v30n3/27.pdf >. Acesso em: 30 jul. 2013. 